\title{
THE APPLICATIONS OF AHP IN SELECTING IMPORTANT SUBJECTS OF SYNDROME OF THE DEFICENCY OF SPLEEN QI IN TCM
}

\author{
Liu Ming Zhi
}

Hunan College of Traditional Chinese Medicine

\begin{abstract}
This paper investigates 15 experts on TCM by using the Delphi method, and apply AHP and Multi-Superiority Analysis models to select the important research subjects in syndrome of the deficiency of spleen Qi (SUSQ) in TCM. The conclusions coincide with the basic theory of TCM and the clinical experience.
\end{abstract}

\section{INTRODUCTION}

Traditional Chinese Medicine (TCM) holds that the spleen has the functions of transporting and transfoming the food essence, keeping the blood flowing within the blood vessels, opening in the mouth, and it is related with the stomach interior-exteriorly.

Dysfunction of the spleen in transportation and transformation (DSTT) may result in the symptoms such as poor appetite, distention of abdomen, loose slooes, and lassitude etc.. called as the syndrome of deficiency of the spleen Qi (SDSQ), which is commonly seen in the clinic. Proceeding from the dialectical materialist point of view and the organic concept in TCM, the normal function of the spleen in transportation and transformation is in need of the cooperation with other internal organs, especially with stomach. Therefore, the syndrome of deficiency of the spleen Qi is an important subject in TCM research work, in which a lot of items are involved. In the clinical observations, the syndrome of deficiency of the spleen Qi is considered to be interrelated with the excretion of gastrin, gastric juice and saliva etc.. In order to explore the nature of syndrome of deficiency of the spleen $Q i$ and reduce the repeat research work, we investigate fifteen experts on TCM (e. g. The Basic Theory of TCM, Internal Medicine, Diagnostics, Physiology, Pathology, and the R\&D Management), and apply Analytical Hierarchical Processes (AHP) and Multi-Superiority Analysis models to select an important one of the three research subjects on DSTT - The relationship between SDSQ and gastrin (D1), SDSQ and the secretion of saliva (D2), and SDSQ and the secretion of gastric juice (D3). The results coincide with the basic theory of TCM and the clinical experience. 
1. Objective Analysis Model

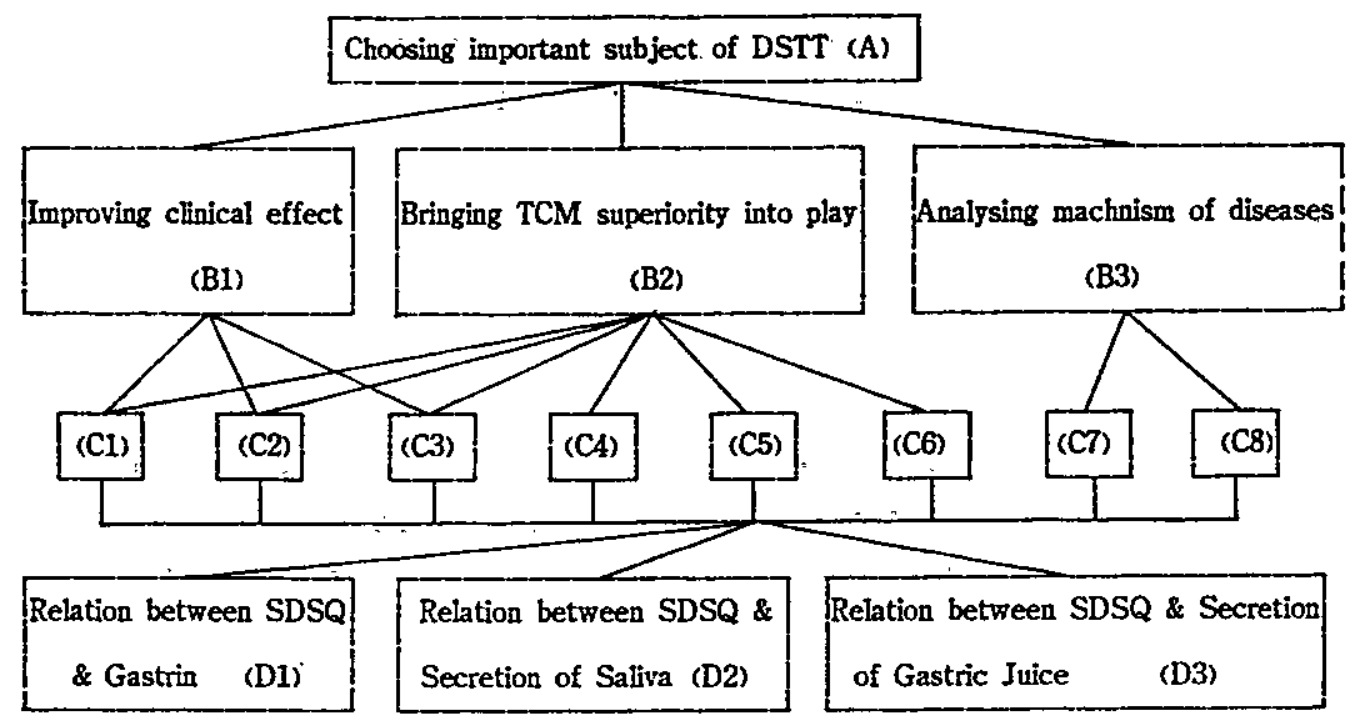

(Figure 1)

$$
\text { wher } \begin{aligned}
\mathrm{A}-\text { Objective Level } \\
\mathrm{B}-\text { Criteria Level } \\
\mathrm{C}-\text { Indicators Level } \\
\text { D } \longrightarrow \text { Research Subjects }
\end{aligned}
$$
C1: Diagnosis
C2: Treatment
C3: Protect

C4: Cultivate Ability C5: Innovation in Research ,

C6: Combination of TCM and Western Medicine (WM)

C7: Organic Concept $\quad$ C8: Dialectical Materialist Point of View

2. Construction of The Judgement Matrices

A-B Judgement Matr.

\begin{tabular}{ccccc}
\hline $\mathrm{A}$ & $\mathrm{B} 1$ & $\mathrm{~B} 2$ & $\mathrm{~B} 3$ & $\mathrm{~W}$ \\
\hline $\mathrm{B} 1$ & 1 & 1 & 2 & 0.4 \\
\hline $\mathrm{B} 2$ & 1 & 1 & 2 & 0.4 \\
\hline $\mathrm{B} 3$ & $1 / 2$ & $1 / 2$ & 1 & 0.2
\end{tabular}

$\lambda(\max )=3 \quad \mathrm{CI}=0, \mathrm{CR}=0$
B1-C Judgement Matr.

\begin{tabular}{ccccc}
\hline $\mathrm{B} 1$ & $\mathrm{C} 1$ & $\mathrm{C} 2$ & $\mathrm{C} 3$ & $\mathrm{~W}$ \\
\hline $\mathrm{C} 1$ & 1 & $1 / 3$ & 1 & 0.2 \\
\hline $\mathrm{C} 2$ & 3 & 1 & 3 & 0.6 \\
\hline $\mathrm{C} 3$ & 1 & $1 / 3$ & 1 & 0.2
\end{tabular}

$\lambda(\max )=3 \mathrm{CI}=0 . \mathrm{CR}=0$.
B3-C.Judgement Matr.

\begin{tabular}{cccc}
\hline $\mathrm{B} 3$ & $\mathrm{C7}$ & $\mathrm{C} 8$ & $\mathrm{~W}$ \\
\hline $\mathrm{C} 7$ & 1 & 1 & 0.5 \\
\hline $\mathrm{C} 8$ & 1 & 1 & 0.5 \\
\hline
\end{tabular}

$\lambda(\max )=2 \quad \mathrm{CI}=0, \mathrm{CR}=0$ 
B2-C Judgement Matrix

\begin{tabular}{|c|c|c|c|c|c|c|c|}
\hline B2 & $\mathrm{Cl}$ & $\mathrm{C} 2$ & $\mathrm{C} 3$ & $\mathrm{CA}$ & C5 & c6 & $w$ \\
\hline $\mathrm{Cl}$ & 1 & $1 / 3$ & 1 & $1 / 3$ & $1 / 3$ & $\overline{2}$ & 0.0893 \\
\hline $\mathrm{C} 2$ & 3 & 1 & 1 & 1 & 1 & 6 & 0.2231 \\
\hline C3 & 1 & 1 & 1 & $1 / 3$ & $1 / 3$ & 2 & 0.1072 \\
\hline $\mathrm{C} 4$ & 3 & 1 & 3 & 1 & 1 & 6 & 0.2679 \\
\hline C5 & 3 & 1 & 3 & 1 & 1 & 6 & 0.2679 \\
\hline C6 & $1 / 2$ & $1 / 6$ & $1 / 2$ & $1 / 6$ & $1 / 6$ & 1 & 0.0446 \\
\hline
\end{tabular}

3. a) Computing weights of the factors in indicators level by using AHP model. (see List 1)

b) Coputing the composite evaluation values by using the Multi-Superiority Analysis model. (see List 2)

List 1 Computing the weight of the factor in indicators level

\begin{tabular}{|c|c|c|c|c|c|}
\hline \multirow{2}{*}{ Factor } & \multicolumn{3}{|c|}{ Weight of factor in crteria level } & \multirow{2}{*}{\multicolumn{2}{|c|}{$\begin{array}{l}\text { Weight of factor in } \\
\text { indicators level }\end{array}$}} \\
\hline & B1 $(0.4)$ & B2 $(0.4)$ & B3 $(0.2)$ & & \\
\hline C1 & 0.2 & 0.0893 & 0. & & 0.1157 \\
\hline $\mathrm{C} 2$ & 0.6 & 0.2231 & 0 . & & 0.3292 \\
\hline $\mathrm{C3}$ & 0.2 & .0 .1072 & 0. & & 0.1229 \\
\hline $\mathrm{CA}$ & .0 . & 0.2679 & 0. & & 0.1072 \\
\hline C5 & 0. & 0.2679 & 0. & & 0.1072 \\
\hline C6 & 0. & 0.0446 & 0. & 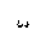 & 0.0178 \\
\hline $\mathrm{C} 7$ & 0. & 0. & 0.5 & & 0.1000 \\
\hline $\mathrm{C} 8$ & 0. & 0. & 0.5 & & 0.1000 \\
\hline
\end{tabular}

List 2 Composite judgement value of the research subject

8

\begin{tabular}{cccccccc}
\hline Factor & $\begin{array}{c}\text { Weight in } \\
\text { AHP }\end{array}$ & $\begin{array}{c}\text { Score } \\
\text { D1 }\end{array}$ & $\begin{array}{c}\text { given dy } \\
\text { D2 }\end{array}$ & $\begin{array}{c}\text { experts } \\
\text { D3 }\end{array}$ & $\begin{array}{c}\text { Composite } \\
\text { D1 }\end{array}$ & $\begin{array}{c}\text { Judgement } \\
\text { D2 }\end{array}$ & $\begin{array}{c}\text { value } \\
\text { D3 }\end{array}$ \\
\hline C1 & 0.1157 & 3.5 & 3.0 & 3.5 & 0.4050 & 0.3472 & 0.4050 \\
C2 & 0.3292 & 5.0 & 2.0 & 3.0 & 1.6462 & 0.6585 & 0.9877 \\
C3 & 0.1229 & 3.0 & 3.5 & 3.5 & 0.3686 & 0.4301 & 0.4301 \\
C4 & 0.1072 & 4.0 & 2.5 & 3.5 & 0.4288 & 0.2679 & 0.3751 \\
C5 & 0.1072 & 4.0 & 2.5 & 3.5 & 0.4288 & 0.2679 & 0.3751 \\
C6 & 0.0178 & 3.5 & 3.0 & 3.5 & 0.0624 & 0.0535 & 0.0624 \\
C7 & 0.1000 & 4.0 & 2.5 & 3.5 & 0.4000 & 0.2500 & 0.3500 \\
C8 & 0.1000 & 4.0 & 2.5 & 3.5 & 0.4000 & 0.2500 & 0.3500 \\
\hline Total & Weight & & & & 4.1396 & 2.6323 & 3.2282 \\
\hline
\end{tabular}


4. Making decisions on the basis of the computed results

The above results suggest that the most important research subject is the-relationship between SDSQ and gastrin (D1), the second SDSQ and the secretion of gastric juice (D3), and the third SDSQ and the secretion of saliva (D2). So we should in emphasis support the research subject (D1).

\section{CONCLUSIONS}

There exist a lot of uncertain factor in the study of TCM. The diagnoses and treatments in TCM are primarily determinated on the basis of doctors and experts' experience and knowledge. The information basis of AHP is the experts' experience and knowledge, and AHP can deal with the complicated, uncertain problems in socio-economic sysetems. Therefore we believe that AHP model will play a very important role in the research of TCM. This paper first apply AHP modle in selecting the important research subjects occuring in TCM. Aithough the method is comparatively simple; "the results obtained in the paper is rather satisfied. We provide the decision-maker with strategic suggestions by analysing the computed results. We think that the further studies should concentrate on following fields: the first is how to select the appropriate research subjects in TCM, the second is to apply AHP model in the diagnoses and treatments of various complicated and unceitain symptoms and quantify the doctors and experts' suggestions. So that we can propose 'various policy suggestions for the decision-makers.

\section{ACKNOWLEDGEMENT}

I am very obliged to Prof. Zheng Ming $\mathrm{Ji}$ and $\mathrm{Mr}$. Shi Lin He. They give me a lot of hard comments, illuminating the structure of the entire paper.

\section{REFERENCE}

Saaty, T.L. and G.V. Lwis, The. Logic of Priorities. Kluwer Boston, Inc., Hingham. Massachusetts, 1982.

Bao, L. and X. Shu Bo, The Tool of Decision and Programming - AHP Model. (in Chinese), Systems Engineering, 2, 2 (1984). 